\title{
An Extracellular Protease of Pseudomonas fluorescens Inactivates Antibiotics of Pantoea agglomerans
}

\author{
L. Meadow Anderson, Virginia O. Stockwell, and Joyce E. Loper
}

First and third authors: U.S. Department of Agriculture-Agricultural Research Service, Horticultural Crops Research Laboratory, 3420 NW Orchard Avenue, Corvallis, Oregon 97330; and second author: Department of Botany and Plant Pathology, Oregon State University, Corvallis 97331.

Current address of L. M. Anderson: Department of Chemistry, University of California, Berkeley 94720.

Accepted for publication 12 July 2004.

\begin{abstract}
Anderson, L. M., Stockwell, V. O., and Loper, J. E. 2004. An extracellular protease of Pseudomonas fluorescens inactivates antibiotics of Pantoea agglomerans. Phytopathology 94:1228-1234.

Pseudomonas fluorescens A506 and Pantoea agglomerans strains Eh252 and C9-1 are biological control agents that suppress fire blight, an important disease of pear and apple caused by the bacterium Erwinia amylovora. Pseudomonas fluorescens strain A506 suppresses disease largely through competitive exclusion of E. amylovora on surfaces of blossoms, the primary infection court, whereas Pantoea agglomerans strains Eh252 and C9-1 produce antibiotics that are toxic to E. amylovora. In this study, an extracellular protease produced by A506 is characterized and evaluated for its capacity to inactivate the antibiotics produced

indicating that the protease is an alkaline metalloprotease. In an agar plate bioassay, partially purified extracellular protease inactivated the antibiotics mccEh 252 and herbicolin $\mathrm{O}$, which are produced by Pantoea agglomerans strains Eh252 and C9-1, respectively. Derivatives of A506 deficient in extracellular protease production were obtained by transposon mutagenesis, and the aprX gene encoding the protease was cloned and sequenced. Strain A506 inactivated mccEh252 and herbicolin O in agar plate bioassays, whereas the $\operatorname{aprX}$ mutant did not inactivate the antibiotics. Both A506 and the $a p r X$ mutant were insensitive to antibiosis by C9-1 and Eh252; thus, the protease was not required to protect A506 from antibiosis. These data highlight a previously unknown role of the extracellular protease produced by Pseudomonas fluorescens A506 in interactions among plant-associated microbes.
\end{abstract} by the strains of Pantoea agglomerans. Activity of the extracellular protease was optimal at $\mathrm{pH} 9$ and inhibited by zinc- or calcium-chelators,
Additional keyword: Erwinia herbicola.
Biological control is a promising approach for management of plant diseases but its use in commercial agriculture remains limited. Among the factors that limit the adoption of biological control into mainstream agriculture is the variation in efficacy that characterizes many biological control systems. One approach toward enhancing the reliability of biological control has been to combine biological control agents into mixtures, which can provide more effective and consistent disease suppression than is attained by application of individual agents $(7,11,13,23,24)$. The compatibility of the biological control agents is recognized as an important factor in designing such mixtures, and monitoring the population sizes of all microbial components in the mixture is typically advised to assure that the biological control agents do not antagonize one another in the formulation or, after application, on plant surfaces. Aside from that compatibility, however, factors influencing the success of biological control mixtures are poorly understood. In this study, we explored a second factor for consideration in designing mixtures of biological agents: the capacity of one biological control agent to interfere with the biological control activity of another. Specifically, we describe a mechanism by which the biological control agent Pseudomonas fluorescens A506 interferes with the inhibition of Erwinia amylovora, the fire blight pathogen, by a second biological control agent, Pantoea agglomerans.

Corresponding author: V. O. Stockwell

E-mail address: stockwev@science.oregonstate.edu

Publication no. P-2004-0916-02R

This article is in the public domain and not copyrightable. It may be freely reprinted with customary crediting of the source. The American Phytopathological Society, 2004.
Fire blight is a major disease of pear and apple that was once controlled by application of commercial antibiotics. The emergence of streptomycin-resistant strains of E. amylovora (22) made it necessary to develop alternate methods for managing the disease. One such approach is biological control achieved by application of nonpathogenic bacterial antagonists of E. amylovora to blossoms, the primary site of infection by the fire blight pathogen (33). Pseudomonas fluorescens strain A506, a commercially available biological control agent for fire blight, suppresses the growth of E. amylovora on stigmatic surfaces of blossoms through preemptive exclusion (38). Preemptive exclusion is a process whereby the biological control agent suppresses growth of the pathogen by prior colonization of physical sites and utilization of limited resources required by the pathogen (38). The epiphytic bacteria Pantoea agglomerans (syn. Erwinia herbicola) strains Eh252 and C9-1 also are used experimentally to suppress populations of E. amylovora on blossom surfaces and limit severity of fire blight disease in pear and apple orchards (14-16,34$37,40)$. Each biocontrol agent suppresses fire blight by an average of $50 \%$, but the level of disease control varies among field trials $(15,20,21,34,35)$. In an effort to improve the biological control of fire blight, combinations of A506 and strains of Pantoea agglomerans have been examined for suppression of disease when applied to blossoms as a mixture. Although strain A506 and Pantoea agglomerans successfully co-colonize blossoms, mixtures of these bacteria generally have not been more effective than single strains in controlling fire blight $(14,15,33,35,36)$.

Many strains of Pantoea agglomerans produce one or more compounds inhibitory to E. amylovora $(12,16,37,39,41)$. Strain Eh252 produces a single antibiotic, mccEh252 $(35,37)$, and strain C9-1 produces two distinct antibiotics, herbicolin $\mathrm{O}$ and herbi- 
colin I (12). Pseudomonas fluorescens strain A506 is not sensitive to any of these compounds. Because it produces only one antibiotic, Eh252 provides a simpler system to study the role of antibiotics in disease control, and orchard studies comparing the wild type to a mutant deficient in mccEh 252 production have demonstrated the importance of this antibiotic in disease suppression (34). MccEh252 is sensitive to pronase and proteinase K (37), which suggests that the antibiotic may be susceptible to inactivation on plant surfaces by extracellular proteases produced by coinhabiting microbes such as Pseudomonas fluorescens A506.

Pseudomonas spp. typically produce extracellular proteases (32), which function in bacterial nutrition by hydrolyzing large proteins into readily utilizable peptides (27). Extracellular proteases can also play a role in plant pathogenesis, as demonstrated for the black rot pathogen Xanthomonas campestris pv. campestris (10) and the fire blight pathogen E. amylovora (42). In other bacteria, such as the soft rot strains E. chrysanthemi EC16 (6) and Pseudomonas fluorescens CY091 (18), proteases are produced but not implicated in virulence. Little is known about additional roles for extracellular proteases in plant-microbe interactions.

In this study, we tested the hypothesis that an extracellular protease produced by the biocontrol strain Pseudomonas fluorescens A506 inactivates antibiotics produced by biocontrol strains of Pantoea agglomerans, thereby interfering with antibiosis of the fire blight pathogen E. amylovora by Pantoea agglomerans. The extracellular protease produced by strain A506 was isolated and, like A506 itself, it interfered with antibiosis of E. amylovora by Pantoea agglomerans in culture. Mutants of A506 deficient in extracellular protease production were obtained by transposon mutagenesis, and these mutants did not interfere with antibiosis of E. amylovora by Pantoea agglomerans in culture. Finally, the gene $(\operatorname{apr} X)$ that encodes the extracellular protease was sequenced and the protease was characterized. The findings of this study provide evidence for a new role for the extracellular protease of Pseudomonas fluorescens in microbial interactions: as an agent that can interfere with antibiosis of E. amylovora by strains of Pantoea agglomerans.

\section{MATERIALS AND METHODS}

Bacterial strains, plasmids, and culture conditions. Bacterial strains and plasmids are summarized in Table 1. Cultures for protease assays were grown in a minimal salts (MS) medium (18) containing the following as percents (wt/vol): $\mathrm{K}_{2} \mathrm{HPO}_{4}(0.7 \%)$, $\mathrm{KH}_{2} \mathrm{PO}_{4}(0.7 \%), \mathrm{MgSO}_{4} \cdot 7 \mathrm{H}_{2} \mathrm{O}(0.02 \%),\left(\mathrm{NH}_{4}\right)_{2} \mathrm{SO}_{4}(0.1 \%)$, and glycerol $(0.4 \%)$, or in P2 broth (42). Calcium chloride was added to the media as indicated. Luria-Bertani medium (2) was used routinely for culturing strains of Escherichia coli. All other bacteria were grown on King's medium B (17). When necessary, antibiotics were added to media at the following final concentrations: tetracycline, $50 \mu \mathrm{g} / \mathrm{ml}$ on solid media and $20 \mu \mathrm{g} / \mathrm{ml}$ in broth, and kanamycin, $50 \mu \mathrm{g} / \mathrm{ml}$. E. coli strains were cultured at $37^{\circ} \mathrm{C}$, and all other bacterial cultures were incubated at 27 or $20^{\circ} \mathrm{C}$. Liquid cultures were aerated on a rotary shaker at $200 \mathrm{rpm}$.

Overlay assays. Modification of an overlay assay was used to evaluate the influence of protease on antibiosis of E. amylovora by Pantoea agglomerans. A small volume $(10 \mu \mathrm{l})$ of a cell suspension of Eh252, C9-1, or CIE85 (an E. coli construct that produces herbicolin $\mathrm{O}$ of C9-1) adjusted to an optical density at $600 \mathrm{~nm}$ $\left(\mathrm{OD}_{600 \mathrm{~nm}}\right)$ of $\approx 0.3$ was placed in the center of a petri dish containing MOPS gluconate asparagine (MGA) medium (12) and incubated for $24 \mathrm{~h}$; bacterial cells were removed with cotton swabs and remaining cells were killed by exposure to germicidal UV (two 10-min treatments separated by at least $20 \mathrm{~min}$ ). Pathogen sensitivity to compounds secreted into the medium was determined by overlaying the agar surface with a suspension of log phase cells of E. amylovora strain Ea153 in soft (0.4\% agar)
MGA medium amended with $0.1 \mathrm{mM}$ thiamine and $0.1 \mathrm{mM}$ nicotinic acid. Log phase cells were obtained from an MGA broth culture of E. amylovora with $\mathrm{OD}_{600 \mathrm{~nm}}$ of $\approx 0.3 ; 30 \mu \mathrm{l}$ was used per 4-ml overlay. Once the overlay agar solidified, a sterile cork borer was used to cut $40-\mu \mathrm{l}$ wells through both layers of agar. A $40-\mu \mathrm{l}$ portion of A506 protease, recovered from a Macrosep column (described below), or $40 \mu \mathrm{l}$ of proteinase K $(0.2 \mathrm{mg} / \mathrm{ml})$ (Sigma Chemical, St. Louis) was added to a well. Water, protease samples inactivated by $20 \mathrm{~min}$ of boiling, and $10 \mu \mathrm{l}$ of $1 \mathrm{mM}$ D,L-histidine, which inhibits antibiosis by mccEh252 and herbicolin $\mathrm{O}(12,37)$, served as controls.

Pseudomonas fluorescens strain A506 or the protease-deficient derivative M1 were tested for their influence on antibiosis of E. amylovora by Pantoea agglomerans Eh252 in a modification of the overlay assay described previously. A small volume $(15 \mu \mathrm{l})$ of overnight King's medium B broth cultures of Eh252, M1, and A506 were spotted or streaked on a petri dish containing glucoseasparagine (GA) medium (37) or MGA medium solidified with nobel agar (Difco Laboratories, Detroit, MI) (12) and incubated at $27^{\circ} \mathrm{C}$ for $48 \mathrm{~h}$. The resulting colonies were killed by exposure to chloroform vapors, and the pathogen Ea153 was applied as an overlay as described previously. After incubation at $27^{\circ} \mathrm{C}$ for 48 to $96 \mathrm{~h}$, patterns of inhibition and growth of E. amylovora were recorded.

Mutagenesis and Southern analysis. Mutants of A506 resistant to kanamycin were generated by standard methods (30) for conjugal transfer of the pUT mini-Tn5 Km transposon (9) from strain JL1931 and screened on litmus milk agar (Difco Laboratories) for loss of extracellular protease activity. Genomic DNA of mutants exhibiting decreased proteolysis was extracted by standard CTAB methods and used for Southern blot analysis with the 2.3-kb EcoRI fragment of pUT mini-Tn5 Km as the probe. Southern blot analysis $(2,30)$ was used to determine the number of transposon insertions in selected mutants and to identify enzymes suitable for inverse polymerase chain reaction (PCR). Growth rates of an extracellular protease-deficient transposon mutant of A506 and the wild-type strain A506 were measured as an increase in $\mathrm{OD}_{600 \mathrm{~nm}}$ in triplicate samples of $5 \mathrm{ml}$ of King's medium B broth and MGA broth at $27^{\circ} \mathrm{C}$ at $200 \mathrm{rpm}$ inoculated with $1 \times$ $10^{6} \mathrm{CFU} / \mathrm{ml}$. Similarly, growth of A506 or the protease-deficient mutant in combination with Pantoea agglomerans C9-1 was evaluated in King's medium B broth and MGA broth. Triplicate cultures were inoculated with $5 \times 10^{5} \mathrm{CFU}$ of each strain per ml, and periodically, dilutions of $100-\mu \mathrm{l}$ samples of broth cultures

TABLE 1. Bacterial strains

\begin{tabular}{|c|c|c|}
\hline Strain & Relevant properties ${ }^{\mathrm{z}}$ & $\begin{array}{l}\text { Source or } \\
\text { reference }\end{array}$ \\
\hline \multicolumn{3}{|c|}{ Pseudomonas fluorescens } \\
\hline A506 & $\begin{array}{l}\text { Biological control strain, isolated } \\
\text { from pear in California, Rif } \mathrm{R}\end{array}$ & 19 \\
\hline M1 & aprX::miniTn 5 derivative of A506, $\mathrm{Km}^{\mathrm{R}}$ & This study \\
\hline M13 & gacS::miniTn 5 derivative of $\mathrm{A} 506, \mathrm{Km}^{\mathrm{R}}$ & This study \\
\hline M14 & gacS::miniTn 5 derivative of $\mathrm{A} 506, \mathrm{Km}^{\mathrm{R}}$ & This study \\
\hline \multicolumn{3}{|c|}{ Escherichia coli } \\
\hline JL1931 & $\begin{array}{l}\text { S17-1 } \lambda \text { pir containing pUT miniTn5 } \\
K m, \mathrm{Km}^{\mathrm{R}}, \mathrm{Amp}^{\mathrm{R}}\end{array}$ & 9 \\
\hline CIE85 & $\begin{array}{l}\text { DH5 } \alpha \text { containing pLAFR3 with the } \\
\text { herbicolin } \mathrm{O} \text { biosynthetic region, } \mathrm{Tc}^{\mathrm{R}}\end{array}$ & 8 \\
\hline \multicolumn{3}{|c|}{ Pantoea agglomerans } \\
\hline Eh252 & $\begin{array}{l}\text { Biological control strain, isolated } \\
\text { from apple in New York }\end{array}$ & 37 \\
\hline C9-1 & $\begin{array}{l}\text { Biological control strain, isolated } \\
\text { from apple in Michigan }\end{array}$ & 12 \\
\hline \multicolumn{3}{|c|}{ Erwinia amylovora } \\
\hline Ea153 & $\begin{array}{l}\text { Fire blight pathogen, isolated from } \\
\text { apple in Oregon }\end{array}$ & 15 \\
\hline
\end{tabular}

Vol. 94, No. 11, 2004 
were spread on the surface of solidified King's medium B. Colonies of Pseudomonas fluorescens A506 and Pantoea agglomerans C91 were distinguished by pigmentation and morphology. Growth rate experiments were repeated.

PCR and sequence analysis. Genomic DNA from each mutant was digested with $\mathrm{NcoI}$, extracted with phenol/chloroform, ethanol precipitated, and brought to a final concentration of $10 \mathrm{ng} / \mu \mathrm{l}$ prior to self-ligation with T4 DNA ligase. Self-ligated, circular DNA containing portions of mini-Tn $5 \mathrm{Km}$ were amplified by PCR. The PCR primers were obtained from Macromolecular Resources (Fort Collins, CO) or Integrated DNA Technologies (Coralville, IA). The primer mTn5ends (5'-CGGTTTACAAGCATAAAGCTTGC-3'), complementary to bases $62-84$ and identical to bases 2252-2274 of mini-Tn5 Km (GenBank accession no. U32991) was used to amplify both circular DNAs. The second primer in each reaction was either mTn5NcoF (5'-GAGAGGCTATTCGGCTATGACTGG-3'), identical to bases 905928 of mini-Tn5 Km, or mTn5NcoR (5'-AACGCTATGTCCTGATAGCGGTCC-3'), complementary to bases 1501-1521. Amplification using Elongase (Invitrogen, Carlsbad, CA) was accomplished according to manufacturers recommendations and under the following reaction conditions: $3 \mathrm{~min}$ at $94^{\circ} \mathrm{C}$; 35 cycles of $1 \mathrm{~min}$ at $94^{\circ} \mathrm{C}, 1 \mathrm{~min}$ at $55^{\circ} \mathrm{C}$, and $5 \mathrm{~min}$ at $68^{\circ} \mathrm{C}$; and $10 \mathrm{~min}$ at $68^{\circ} \mathrm{C}$. The PCR products were sequenced at the Center for Gene Research and Biotechnology, Oregon State University. BLAST searches of GenBank (1) using the resulting sequences were used to identify the gene disrupted by mini-Tn5 $\mathrm{Km}$ in each mutant. Additional protease gene sequence was obtained using the primers aprXf5 (sense, 5'-AAATAGTGGTGTGCGCCGATTCG$3^{\prime}$ ) with aprXr3 (antisense, 5'-CATACCGAGAACACCAGCTTGTCG-3') and aprXf3 (sense, 5'-CAGTTCCAATGCCGACAAGCTGG-3') with aprXr2 (antisense, 5'-GCTCCTGCCGACACGAACAACAC-3'). Taq polymerase was used according to supplier recommendations (Invitrogen, Carlsbad, CA) and the following conditions were used for amplification: $2 \mathrm{~min}$ at $94^{\circ} \mathrm{C} ; 35$ cycles of $45 \mathrm{~s}$ at $94^{\circ} \mathrm{C}, 1 \mathrm{~min}$ at $55^{\circ} \mathrm{C}$, and $3 \mathrm{~min}$ at $72^{\circ} \mathrm{C}$; and $10 \mathrm{~min}$ at $72^{\circ} \mathrm{C}$. Vector NTI software (version 8; InforMax, North Bethesda, MD) was used for sequence analyses and the MEROPS database (28) was used for classification.

Protease production and purification. Cell-free filtrate $(0.2 \mu \mathrm{m})$ from a $500-\mathrm{ml}, 2$-day culture of A506 grown with agitation at $20^{\circ} \mathrm{C}$ in $\mathrm{MS}$ supplemented with $0.2 \mathrm{mM} \mathrm{CaCl}_{2}$ was lyophilized and resuspended in $10 \mathrm{ml}$ of water. Protease activity of the supernatant was determined using hide powder azure (Sigma Chemical) as a substrate (18). In preliminary studies, freezing and thawing did not alter activity of the protease, so supernatants often were stored at $-20^{\circ} \mathrm{C}$ and then analyzed at one time to reduce variability in assay conditions. After centrifugation to remove solids $(5 \mathrm{~min}, 2,500 \times g)$, the supernatant was applied to a gel filtration column $(1.75$ by $14 \mathrm{~cm})$ packed with Sephadex G-50-80 (Sigma Chemical). The column was pre-equilibrated with $50 \mathrm{mM}$ Tris- $\mathrm{HCl}$ ( $\mathrm{pH} 8.0)$, which was used for elution. Protease activities of $1-\mathrm{ml}$ fractions were measured using hide powder azure. Purity was determined by sodium dodecyl sulfatepolyacrylamide gel electrophoresis (SDS-PAGE) as described below. The other method of protease preparation was filtration with an Omega Macrosep 10K centrifugal unit (VWR, Brisbane, CA). Culture filtrate was reduced to $1 / 25$ volume by centrifugation in a swinging bucket rotor at $4,000 \times g$ for $120 \mathrm{~min}$.

Protease electrophoresis. Supernatants from broth cultures were evaluated in polyacrylamide gels for detection and size determination of extracellular proteases. Samples were applied to a Zymogram (Bio-Rad Laboratories, Hercules, CA), a 10\% polyacrylamide gel containing $1 \%$ gelatin as a protease substrate. The zymogram was renatured to remove SDS, incubated in a calciumcontaining buffer to allow enzyme proteolysis, and stained with Coomassie blue $\mathrm{R}$ according to the recommendation of Bio-Rad Laboratories. After destaining, clear regions were visible in areas where the gelatin had been degraded by an active protease. Standard $12 \%$ Tris-HCl SDS-PAGE gels stained with silver for detection (2) were used to verify purity of protease preparations.

Characterization of enzyme activity. Optimal $\mathrm{pH}$ for protease activity was determined in $50 \mathrm{mM}$ solutions of the following buffers, each containing $1 \mathrm{mM} \mathrm{CaCl}$ : citric acid/sodium citrate $(\mathrm{pH}$ 3.0, 5.0, and 6.0), acetic acid/sodium acetate $(\mathrm{pH} 4.0$ and 5.0), Tris- $\mathrm{HCl}$ (pH 7.0, 8.0, and 9.0), and glycine (pH 10.0 and 11.0). Approximately 3 units ( $20 \mu \mathrm{l}$ of partially purified sample) of enzyme were preincubated in the buffer solution for $30 \mathrm{~min}$ prior to the hide powder azure assay (18). Controls in which the enzyme was replaced with water were evaluated at each $\mathrm{pH}$ value to correct for nonenzymatic proteolysis. Inhibition by EDTA, EGTA, 1,10-phenanthroline, and excess calcium was determined by a similar method: partially purified enzyme was preincubated with the inhibitor in modified assay buffer $(50 \mathrm{mM}$ Tris- $\mathrm{HCl}$ [pH 8.0], no $\mathrm{CaCl}_{2}$ ) for $30 \mathrm{~min}$ before the hide powder azure assay. A parallel assay in which the inhibitor was replaced with the appropriate solvent served as the control. All experiments were repeated and contained at least two replicates.

Comparison of proteases of biocontrol strains and $E$. amylovora. Relative protease activity of the pathogen and biological control strains was determined in 48-h cultures of P2 broth, the medium used for characterization of the extracellular protease of E. amylovora (42). Protease activity of the supernatant was determined with the hide powder azure assay. Supernatants of each of the strains also were examined with a zymogram. All experiments were repeated and contained at least two replicates.

Data analysis. The percent inhibition data were arcsine square root-transformed before mean separation by Fisher's protected least significant difference test at $P=0.05$ using the analysis of variance procedure of Statistical Analysis Systems (SAS Institute, Cary, NC).

Nucleotide sequence accession number. Sequence of the $a p r X$ gene of Pseudomonas fluorescens A506 is deposited in the GenBank database under accession no. AY298902.

\section{RESULTS}

Inactivation of antibiotics produced by Pantoea agglomerans strains Eh252 and C9-1 by the extracellular protease of Pseudomonas fluorescens strain A506. Pantoea agglomerans strains C9-1 and Eh252 produce zones of inhibition against E. amylovora on MGA and GA media that are attributed to their production of antibiotics $(12,37)$. Extracellular protease partially purified and concentrated from culture supernatant of A506 allowed growth of $E$. amylovora within the zones of inhibition that surrounded colonies of Pantoea agglomerans Eh252 (which produces mccEh252) or an E. coli strain that produces herbicolin $\mathrm{O}$ by heterologous expression of biosynthesis genes cloned from C9-1 (Fig. 1). Commercially prepared proteinase $\mathrm{K}$ and histidine, an inhibitor of mccEh252 and herbicolin O, also allowed growth of E. amylovora within the zones of inhibition. Boiled, inactive preparations of proteinase $\mathrm{K}$ or the extracellular protease of A506 did not allow pathogen growth within the inhibition zones of mccEh 252 and herbicolin $\mathrm{O}$ (data not shown). These results indicate that proteolysis of mccEh 252 and herbicolin $\mathrm{O}$ by proteinase $\mathrm{K}$ and by the extracellular protease of A506 renders these antibiotics ineffective in inhibiting growth of E. amylovora. Similar results were obtained when C9-1 was the antibiotic-producing strain in the assay, but the area of protease-facilitated pathogen growth was less distinct near the center of the inhibition zone, where a second, protease-insensitive antibiotic called herbicolin I was present (data not shown).

Derivation of extracellular protease mutants of Pseudomonas fluorescens strain A506. Like the proteases described previously, Pseudomonas fluorescens A506 also interfered with antibiosis of E. amylovora by Eh252 on MGA medium and GA 
medium (Fig. 2). To determine if the extracellular protease produced by A506 was responsible for this inactivation, we derived and characterized mutants of A506 that lack extracellular protease production.

Of approximately 4,000 transposon mutants of A506 that were screened for extracellular protease production on litmus milk agar, three mutants (M1, M13, and M14) carried single transposon insertions, had altered protease activity, and were characterized further. After several days of growth on litmus milk agar, M13 and M14 exhibited very weak proteolysis, whereas M1 exhibited no detectable protease activity.

Sequence of the PCR products amplified from DNA flanking the insertion sites indicated that both M13 and M14 have a transposon insertion in gacS, a known regulator of extracellular protease production in Pseudomonas spp. (5). The transposon insertions in M13 and M14 are located within the same 15 base pair region, which aligns with nucleotides 330-345 of gacS of Pseudomonas synthaxa (GenBank accession no. AY027925), but the insertions are in opposite orientation to one another. The sequences of DNA immediately upstream of both insertions had $86 \%$ identities to gacS of Pseudomonas synthaxa over the 263- or 266-bp portions amplified. The downstream portions are $89 \%$ identical over 177 or $181 \mathrm{bp}$. These pleiotropic mutants were not further characterized.

Sequence analysis of an inverse PCR product indicated that M1 has a transposon insertion between nucleotides 1130 and 1140 of the structural protease gene $a p r X$. The nucleotide sequences of the 1.4-kb aprX genes from CY091 (GenBank accession no. AF004848) and A506 are 89\% identical. The predicted product of $a p r X$ is a protein with a molecular weight of $49.5 \mathrm{kDa}$ and belongs to the subfamily M10B of the MA(M) peptidase clan, which is characterized by a zinc-binding HEXXHXXGXXH motif and a conserved tyrosine residue in the active site. The predicted amino acid sequence of AprX also contains four $\mathrm{Ca}^{2+}$ binding motifs (GGXGXD), which are also present in AprX from Pseudomonas fluorescens CY091 and serralysin, the MEROPS protease subfamily M10B-type example from Serratia marcescens (Fig. 3). Ion binding at these sites has been confirmed in the crystal structure of serralysin (4).

An aprX mutant of Pseudomonas fluorescens strain $\mathbf{A 5 0 6}$ does not interfere with antibiosis of $E$. amylovora by biocontrol strains of Pantoea agglomerans. The aprX mutant M1 was compared with the wild-type strain A506 in plate assays to determine if AprX is responsible for the capacity of A506 to inactivate antibiotics produced by biocontrol strains of Pantoea agglomerans. The zone of inhibition surrounding strain Eh252 was visible on the agar surface surrounding the $\operatorname{aprX}$ mutant M1 (Fig. 2), indicating that the aprX mutant did not inactivate mccEh252. By comparing A506 and M1, the capacity to interfere with antibiosis was attributed to the extracellular protease, which was produced by A506 but not by the aprX mutant M1. Colonies of A506 and M1 grew immediately adjacent to Eh252 and C9-1 (data not shown), indicating that AprX was not required for antibiotic resistance of A506. When grown in King's medium B broth or MGA broth, either alone or in combination with Pantoea agglomerans C9-1, the growth rates of A506 and M1 were indistinguishable (data not shown).

Altered extracellular protease production by the $a p r X$ and gacS mutants of Pseudomonas fluorescens strain A506. The approximate $50-\mathrm{kDa}$ protein present in supernatants of A506 cultures was not detected in cultures of the $a p r X$ mutant when evaluated by SDS-PAGE with silver staining or in a zymogram (data not shown). These data confirm that the aprX mutants, which were selected for lack of protease production on litmus milk agar, are deficient in extracellular protease production. When 5-day-old culture supernatant from the gacS mutants was electrophoresed in the denaturing SDS zymogram gel, a faint proteolytic band that migrates at a slightly larger apparent molecular weight than AprX was observed (data not shown). This indicates that the protease responsible for the slight proteolysis exhibited on litmus milk agar by the gacS mutants M13 and M14 differs from AprX of A506, but the nature of the protease was not investigated further. The absence of this band in cultures of the aprX mutant suggests that its presence is related to the gacS phenotype.

Biochemical characterization of the extracellular protease produced by Pseudomonas fluorescens strain A506. In supernatants of A506 cultures grown for $48 \mathrm{~h}$ in the chemically defined MS medium, the extracellular protease was the only band detected by SDS-PAGE with silver staining and had a molecular weight of approximately $50 \mathrm{kDa}$ (data not shown). Apparently, AprX was the predominant protein secreted by A506 under these culture conditions. Gel filtration of lyophilized culture filtrate provided an extracellular protease preparation of sufficient purity for biochemical assays. Activity was concentrated 25 -fold by gel filtration. Zymogram analysis indicated the presence of a single protease in the concentrated samples. Samples of the concentrated protease preparation electrophoresed to a single band in silverstained SDS gels; no other proteins were detected. The protease of A506 had optimal activity in moderately alkaline conditions, with less than $50 \%$ activity retained below $\mathrm{pH} 6$ or above $\mathrm{pH} 10$ (Fig. 4). Of the three metal-chelators tested as protease inhibitors (Table 2), zinc-binding 1,10-phenathroline had the highest inhibitory activity. Inhibition by 1,10 -phenanthroline provided evidence that zinc is utilized in the active site (25). Calcium-specific EGTA
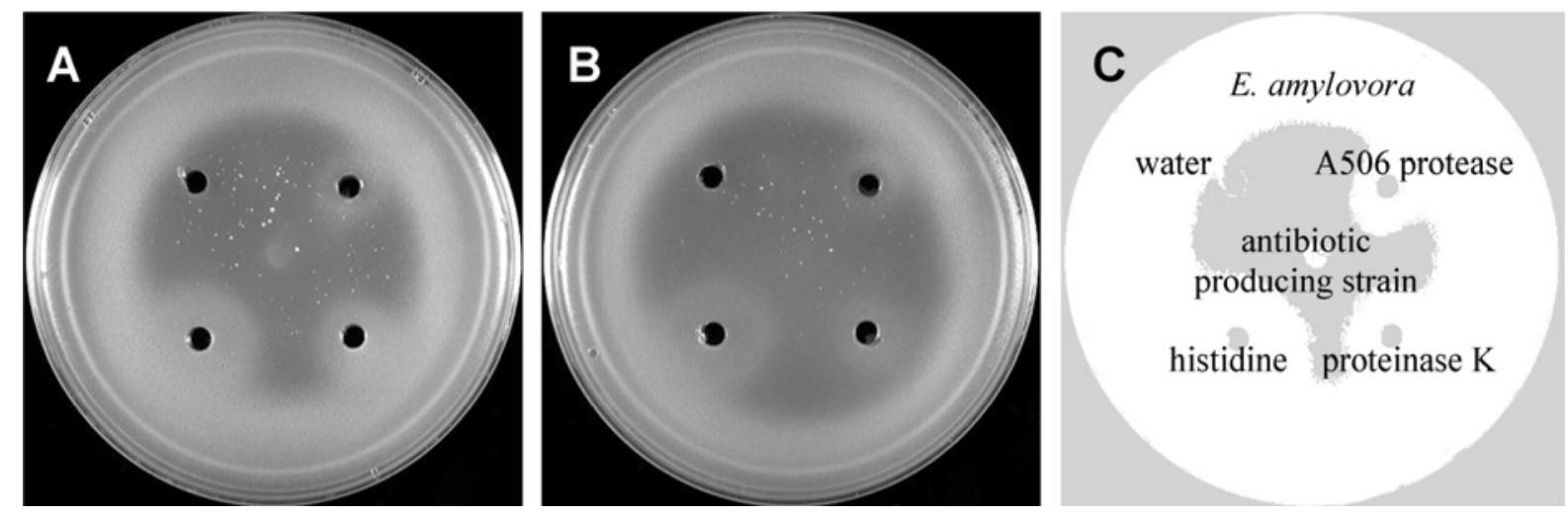

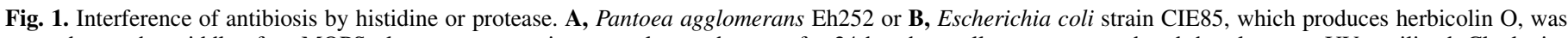

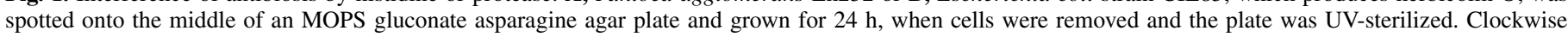

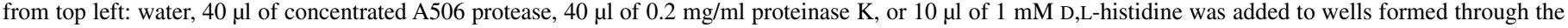

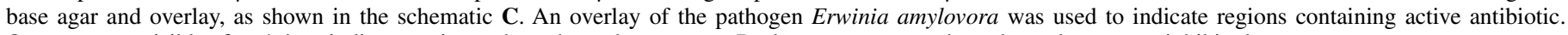
Opaque areas visible after 4 days indicate regions where the pathogen grew. Dark gray areas are where the pathogen was inhibited. 
caused some loss of protease activity, but EDTA, which chelates both calcium and zinc, caused a greater reduction. Addition of $1 \mathrm{mM} \mathrm{CaCl} 2$ had no measurable effect on protease activity, but $10 \mathrm{mM} \mathrm{CaCl}$ reduced the activity of extracellular protease. The reduction of $\mathrm{A} 506$ protease activity at high $\mathrm{Ca}^{2+}$ concentration has been observed previously for another metalloprotease (31). Therefore, the extracellular protease produced by A506 has the characteristics of alkaline metalloproteases produced by other strains of Pseudomonas fluorescens and other Pseudomonas spp. $(3,18,27,29)$.

Pseudomonas fluorescens strain A506 produced more protease than E. amylovora or Pantoea agglomerans. Pseudomonas fluorescens strain A506, Pantoea agglomerans strains Eh252 and C9-1, and E. amylovora strain Ea153 produce extracellular proteases, but the A506 protease was present in much higher concentrations than those produced by the other three bacterial species under all conditions tested. In both MS (data not shown) and P2 broth culture, strain A506 produced significantly higher protease activity than Eh252, C9-1, or E. amylovora. The latter three strains did not produce enough activity to be detected using hide powder azure as a substrate. In addition, the extracellular protease of A506 formed a large clearing zone when the bacterium was grown on litmus milk agar, whereas strains Eh252, C9-1, and E. amylovora did not produce detectable clearing zones (data not shown). A zymogram of P2 culture supernatants (Fig. 5) indicated that Eh252, C9-1, and E. amylovora exhibited faint protease activity, but this activity on the gelatin substrate was at least 25fold lower than for A506.
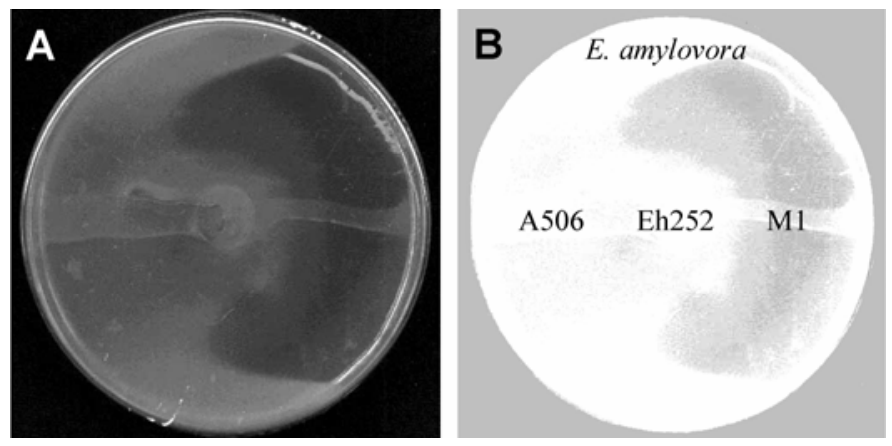

Fig. 2. Comparison of antibiotic inhibition by wild-type A506 and a protease deficient mutant. A, Photograph of the bioassay described below, and $\mathbf{B}$, image A reproduced with labels and higher contrast. Pseudomonas fluorescens A506 (left), Pantoea agglomerans Eh252 (center), and M1, the extracellular protease-deficient mutant of A506 (right) were streaked or spotted onto glucose-asparagine medium solidified with noble agar and grown for $96 \mathrm{~h}$; then colonies were killed by exposure to chloroform vapor. An overlay of the pathogen Erwinia amylovora was used to indicate regions containing active antibiotic. Opaque areas indicate regions where the pathogen grew. Dark areas are where the pathogen was inhibited.

\section{DISCUSSION}

In this study, we demonstrated that the alkaline metalloprotease produced by Pseudomonas fluorescens A506 inactivated two antibiotics produced by strains of Pantoea agglomerans. By inactivating the antibiotics, A506 interfered with in vitro inhibition of

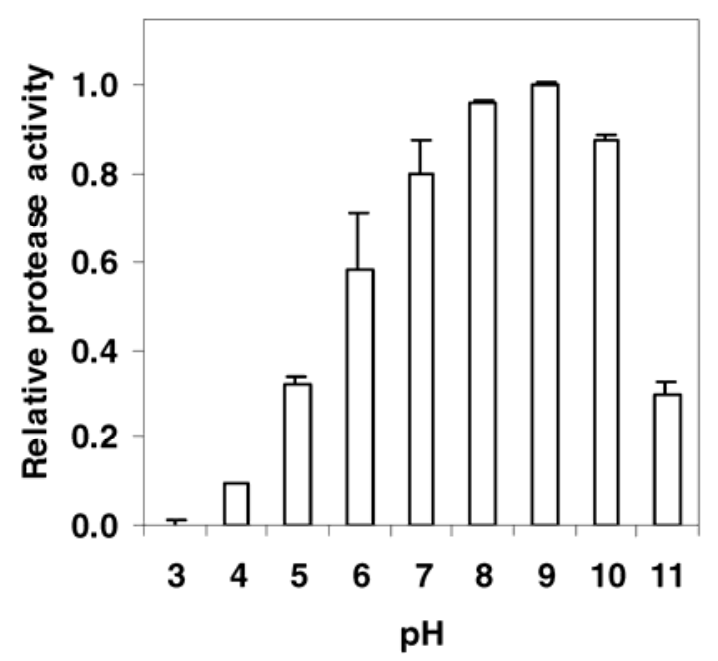

Fig. 4. The effect of $\mathrm{pH}$ on activity of partially purified extracellular protease of Pseudomonas fluorescens A506. Protease was equilibrated in buffer for $30 \mathrm{~min}$ prior to assessing protease activity. Protease activity was quantified as the increase in absorbance at $595 \mathrm{~nm}$ after $1 \mathrm{~h}$ of incubation with hide powder azure, and values have been normalized to the highest activity. Two replicate samples were used. Vertical bars represent the standard deviation. The experiment was repeated and representative results are shown.

TABLE 2. Effects of ion chelators and calcium on activity of the extracellular protease from Pseudomonas fluorescens A506

\begin{tabular}{lcc}
\hline Inhibitor $^{\mathrm{y}}$ & Concentration $(\mathrm{mM})$ & ${\text { Protease activity }(\%)^{\mathrm{z}}}^{\text {None }}$ \\
1,10-Phenathroline & - & $100 \mathrm{a}$ \\
& 1 & $15 \mathrm{~d}$ \\
EGTA & 10 & $1 \mathrm{e}$ \\
& 1 & $75 \mathrm{~b}$ \\
EDTA & 10 & $60 \mathrm{~b}$ \\
& 1 & $62 \mathrm{~b}$ \\
$\mathrm{CaCl}_{2}$ & 10 & $39 \mathrm{c}$ \\
& 1 & $96 \mathrm{a}$ \\
& 10 & $66 \mathrm{~b}$
\end{tabular}

y Protease samples were incubated with an inhibitor of a given concentration for 30 min prior to assessing protease activity with hide powder azure.

${ }^{\mathrm{z}}$ Activities are an average of three experiments of two replicates each and are expressed relative to controls incubated under identical conditions without enzyme inhibitors. Values followed by the same letter do not differ significantly $(P=0.05)$ from one another, as determined by Fisher's protected least significant difference test for arcsine square root-transformed values.

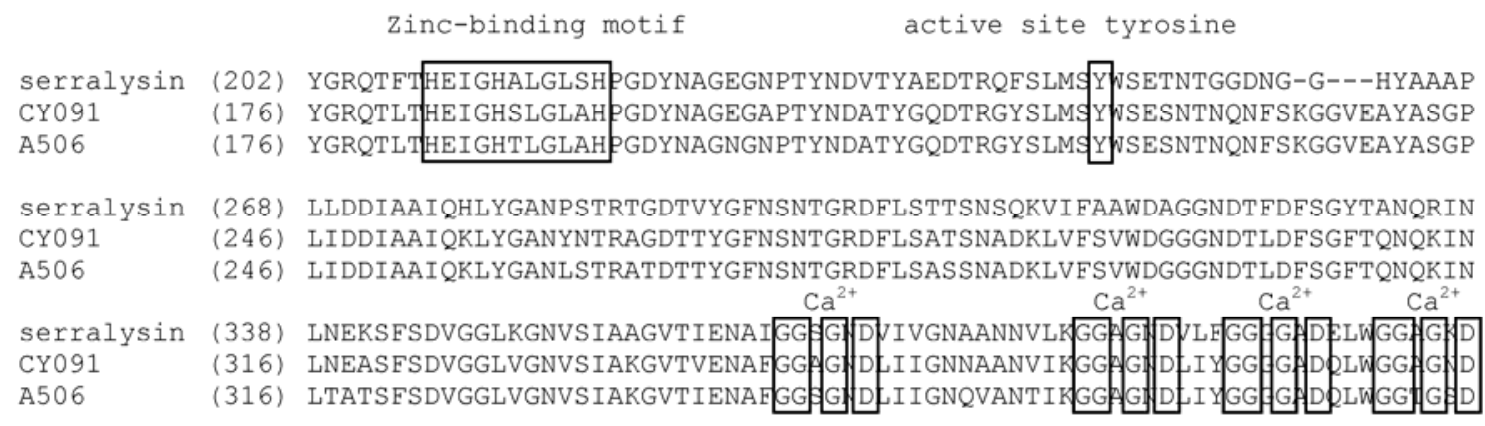

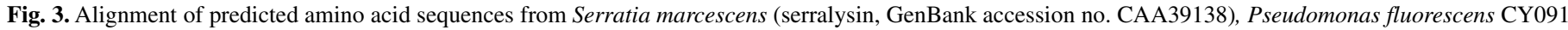

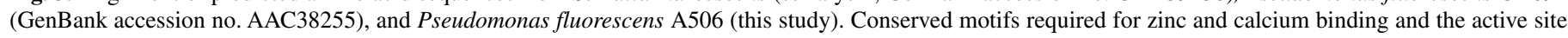
tyrosine residue are boxed. 
the fire blight pathogen E. amylovora by the two strains. E. amylovora also secretes a zinc metalloprotease, which plays a role in the pathogen's invasion of plant host tissue (42). In this study, we detected extracellular protease production by E. amylovora, but at lower activity or total quantity than was observed for strain A506. Additional research is needed to clarify whether the difference in antibiotic inactivation by Pseudomonas fluorescens and E. amylovora is due to specificity, activity, or the level of production of their respective extracellular proteases. The extracellular metalloprotease produced by A506 was not required to protect A506 from antibiosis by Pantoea agglomerans. Nevertheless, it had a critical role in the tri-partite interactions between the two biological control agents and the target pathogen, as an agent that interfered with antibiosis of E. amylovora by strains of Pantoea agglomerans.

Based on biochemical and genetic characterization, AprX was identified as an alkaline metalloprotease that requires zinc and calcium for optimal activity. Protease activity exhibited by AprX of A506 was maximized in alkaline buffers with $\mathrm{pH}$ values of 8 to 10 , but there was substantial residual activity under slightly acidic conditions. The $\mathrm{pH}$ and chemical composition of the stigmatic surface of apple or pear blossoms is unknown and probably vary as blossoms age in exposed environments, but the range over which the protease of A506 is active suggests it will be able to cleave peptide bonds under a variety of conditions.

The structures of herbicolin $\mathrm{O}$ and mccEh252, produced by Pantoea agglomerans strains C9-1 or Eh252, respectively, have not been published, but our results demonstrating that both were inactivated by the exoprotease of A506 indicates that each contains at least one peptide bond. Previous reports indicated that these antibiotics differed in their sensitivity to proteolysis. Vanneste et al. (37) reported that mccEh252 is sensitive to proteolysis by pronase and proteinase K, whereas Ishimaru et al. (12) reported that herbicolin $\mathrm{O}$ is unaffected by the proteolytic enzymes pronase and trypsin. Apparent discrepancies between these reports are likely to be resolved once chemical structural data for both antibiotics becomes available.

Antibiotics produced by biological control agents play a key role in the suppression of many plant diseases. Thus, the stability of antibiotics may affect the success of biological control. The findings of this study established that herbicolin $\mathrm{O}$ and mccEh252 are subject to inactivation by proteases, including the extracellular protease produced by a strain of Pseudomonas fluorescens that inhabits plant surfaces. Strains of Pantoea agglomerans that produce antibiotics are among the most effective known agents for the biological control of fire blight $(14,16,26,33,35,39-41)$ and antibiotic production is an important contributor to this biological control $(34,35,40)$. Nevertheless, antibiotic-producing strains fail to suppress the disease in some orchard environments, and the presence of microbial co-inhabitants that produce extracellular

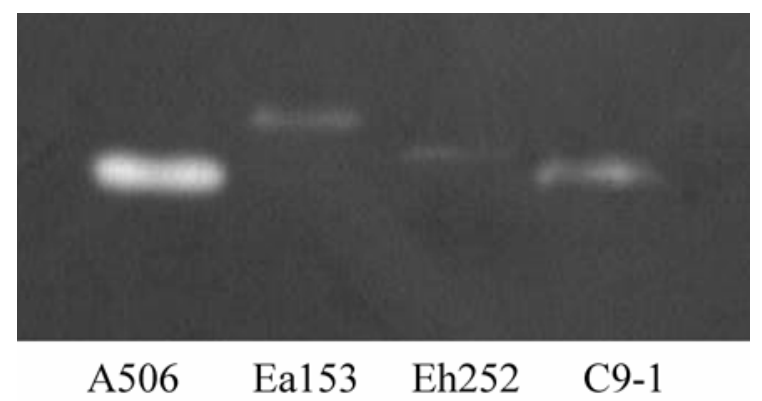

Fig. 5. Comparison of extracellular protease production by different bacterial strains in P2 broth: $0.3 \mu \mathrm{l}$ (for Pseudomonas fluorescens A506) or $3 \mu \mathrm{l}$ (for Erwinia amylovora 153, Pantoea agglomerans Eh252, and Pantoea agglomerans C9-1) of 48-h culture supernatant was electrophoresed in a polyacrylamide gel containing gelatin. Light areas indicate protease capable of degrading the gelatin substrate. proteases on plant surfaces could be one factor impeding the success of biological control in some settings. Extracellular protease production is common among Pseudomonas spp. and other microorganisms that inhabit the plant surfaces $(5,6,10,18,29,42)$. The finding that strain A506 inactivates antibiotics produced by Pantoea agglomerans also provides insight into ways to improve mixtures of the two biological control organisms for suppression of fire blight in the field. Ongoing field experiments evaluating an aprX mutant of A506 for biological control of fire blight alone and in combination with Pantoea agglomerans should provide further insight into the importance of the extracellular protease in microbial interactions on plant surfaces.

\section{ACKNOWLEDGMENTS}

This study was supported in part by grants from the USDA NRICGP 9702924, the Winter Pear Control Committee, and the Howard Hughes Medical Institute Summer Undergraduate Research program at Oregon State University. We thank C.-H. Liao and C. Ishimaru for providing strains CY091 and CIE85, respectively, and for their thoughtful reviews of the manuscript; and M. Brodhagen, N. Chaney, N. Corbell, M. Henkels, B. Shaffer, C. Whistler, and other members of J. Loper's group for insightful comments and technical assistance.

\section{LITERATURE CITED}

1. Altschul, S. F., Madden, T. L., Schäffer, A. A., Zhang, J., Zhang, Z., Miller, W., and Lipman, D. J. 1997. Gapped BLAST and PSI-BLAST: A new generation of protein database search programs. Nucleic Acids Res. 25:3389-3402.

2. Ausubel, F. M., Brent, R., Kingston, R. E., Moore, D. D., Seidman, J. G., Smith, J. A., and Struhl, K. (ed.) 1995. Current Protocols in Molecular Biology. John Wiley \& Sons, New York.

3. Barach, J. T., Adams, D. M., and Speck, S. L. 1976. Stabilization of a psychotropic Pseudomonas protease by calcium against thermal inactivation in milk at ultrahigh temperature. Appl. Environ. Microbiol. 31:875-879.

4. Baumann, U. 1994. Crystal structure of the $50 \mathrm{kDa}$ metallo protease from Serratia marcescens. J. Mol. Biol. 242:244-251.

5. Corbell, N., and Loper, J. E. 1995. A global regulator of secondary metabolite production in Pseudomonas fluorescens Pf-5. J. Bacteriol. 177:6230-6236.

6. Dahler, G. S., Barras, F., and Keen, N. T. 1990. Cloning of genes encoding extracellular metalloproteases from Erwinia chrysanthemi EC16. J. Bacteriol. 172:5803-5815.

7. Dandurand, L. M., and Knudsen, G. R. 1993. Influence of Pseudomonas fluorescens on hyphal growth and biocontrol activity of Trichoderma harzianum in the spermosphere and rhizosphere of pea. Phytopathology 83:265-270.

8. Davis, L. A., and Ishimaru, C. A. 1993. Cloning and expression of herbicolin $\mathrm{O}$ biosynthesis genes in Escherichia coli. (Abstr.) Phytopathology 83:1339.

9. de Lorenzo, V., and Timmis, K. N. 1994. Analysis and construction of stable phenotypes in gram-negative bacteria with $\operatorname{Tn} 5$ - and $\operatorname{Tn} 10$-derived minitransposons. Methods Enzymol. 235:386-405.

10. Dow, J. M., Clarke, B. R., Milligan, D. E., Tang, J. L., and Daniels, M. J. 1990. Extracellular proteases from Xanthomonas campestris pv. campestris, the black rot pathogen. Appl. Environ. Microbiol. 56:2994-2998.

11. Duffy, B. K., Simon, A., and Weller, D. M. 1996. Combination of Trichoderma koningii with fluorescent pseudomonads for control of take-all of wheat. Phytopathology 86:188-194.

12. Ishimaru, C. A., Klos, E. J., and Brubaker, R. R. 1988. Multiple antibiotic production by Erwinia herbicola. Phytopathology 78:746-750.

13. Janisiewicz, W. 1996. Ecological diversity, niche overlap, and coexistence of antagonists used in developing mixtures for biocontrol of postharvest disease of apples. Phytopathology 86:473-479.

14. Johnson, K. B., and Stockwell, V. O. 1998. Management of fire blight: A case study in microbial ecology. Annu. Rev. Phytopathol. 36:227-248.

15. Johnson, K. B., Stockwell, V. O., McLaughlin, M. J., Sugar, D. J., Loper, E., and Roberts, R. G. 1993. Effect of bacterial antagonists on establishment of honey bee-dispersed Erwinia amylovora in pear blossoms and on fire blight control. Phytopathology 83:995-1002.

16. Kearns, L. P., and Hale, C. N. 1996. Partial characterization of an inhibitory strain of Erwinia herbicola with potential as a biocontrol agent for Erwinia amylovora, the fire blight pathogen. J. Appl. Bacteriol. 81:369-374.

17. King, E. O., Ward, M. K., and Raney, D. E. 1954. Two simple media for the demonstration of pyocyanin and fluorescein. J. Lab. Clin. Med. 44:301-307. 
18. Liao, C.-H., and McCallus, D. E. 1998. Biochemical and genetic characterization of an extracellular protease from Pseudomonas fluorescens CY091. Appl. Environ. Microbiol. 64:914-921.

19. Lindow, S. E. 1984. Integrated control and role of antibiosis in biological control of fire blight and frost injury. Pages 83-115 in: Biological Control on the Phylloplane. C. Windels and S. E. Lindow, eds. The American Phytopathological Society, St. Paul, MN.

20. Lindow, S. E., McGourty, G., and Elkins, R. 1996. Interactions of antibiotics with Pseudomonas fluorescens A506 in the control of fire blight and frost injury of pear. Phytopathology 86:841-848.

21. Lindow, S. E., and Suslow, T. V. 2003. Temporal dynamics of the biocontrol agent Pseudomonas fluorescens strain A506 in flowers in inoculated pear trees. Phytopathology 93:727-737.

22. McManus, P. S., Stockwell, V. O., Sundin, G. W., and Jones, A. L. 2002. Antibiotic use in plant agriculture. Annu. Rev. Phytopathol. 40:433-465.

23. Paulitz, T. C., Ahmad, J. S., and Baker, R. 1990. Integration of Pythium nunn and Trichoderma harzianum isolate T-95 for the biological control of Pythium damping-off of cucumber. Plant Soil 121:243-250.

24. Pierson, E. A., and Weller, D. M. 1994. Use of mixtures of fluorescent pseudomonads to suppress take-all and improve growth of wheat. Phytopathology 84:940-947.

25. Powers, J. C., and Harper, J. W. 1986. Inhibitors of metalloproteases. Pages 223-224 in: Proteinase Inhibitors. A. J. Barrett and G. Salvesen, eds. Elsevier, New York.

26. Pusey, P. L. 1997. Crab apple blossoms as a model for research on biological control of fire blight. Phytopathology 87:1096-1102.

27. Rao, M. B., Tanksale, A. M., Ghatge, M. S., and Deshpande, V. V. 1998. Molecular and biotechnological aspects of microbial proteases. Microbiol. Mol. Biol. Rev. 62:597-635.

28. Rawlings, N. D., O'Brien, E., and Barrett, A. J. 2002. MEROPS: The protein database. Nucleic Acids Res. 30:343-346.

29. Sacherer, P., Défago, G., and Haas, D. 1994. Extracellular protease and phospholipase $\mathrm{C}$ are controlled by the global regulatory gene gacA in the biocontrol strain Pseudomonas fluorescens CHA0. FEMS Microbiol. Lett. 116:155-160.

30. Sambrook, J., Fritsch, E. F., and Maniatis, T. 1989. Molecular Cloning: A Laboratory Manual. 2nd ed. Cold Spring Harbor Laboratory, Cold Spring Harbor, NY.
31. Secades, P., Alvarez, B., and Guijarro, J. A. 2001. Purification and characterization of a psychrophilic, calcium-induced, growth-phasedependent metalloprotease from the fish pathogen Flavobacterium psychrophilum. Appl. Environ. Microbiol. 67:2436-2444.

32. Stanier, R. Y., Palleroni, N. J., and Doudoroff, M. 1966. The aerobic pseudomonads: A taxonomic study. J. Gen. Microbiol. 43:159-271.

33. Stockwell, V. O., Johnson, K. B., and Loper, J. E. 2002. Biological control of fire blight: Understanding interactions among introduced and indigenous microbial communities. Pages 225-239 in: Phyllosphere Microbiology. S. E. Lindow, E. I. Hecht-Poinar, and V. J. Elliott, eds. The American Phytopathological Society, St. Paul, MN.

34. Stockwell, V. O., Johnson, K. B., Sugar, D., and Loper, J. E. 2002. Antibiosis contributes to biological control of fire blight by Pantoea agglomerans strain Eh252 in orchards. Phytopathology 92:1202-1209.

35. Vanneste, J. L. 1996. Honey bees and epiphytic bacteria to control fire blight, a bacterial disease of apple and pear. Biocontrol News Inf. $17: 67 \mathrm{~N}-78 \mathrm{~N}$.

36. Vanneste, J. L., and Yu, J. 1996. Biological control of fire blight using Erwinia herbicola Eh252 and Pseudomonas fluorescens A506 separately and in combination. Acta Hortic. 411:351-354.

37. Vanneste, J. L., Yu, J., and Beer, S. V. 1992. Role of antibiotic production by Erwinia herbicola Eh252 in biological control of Erwinia amylovora. J. Bacteriol. 174:2785-2796.

38. Wilson, M., and Lindow, S. E. 1993. Interactions between the biological control agent Pseudomonas fluorescens A506 and Erwinia amylovora in pear blossoms. Phytopathology 83:117-123.

39. Wodzinski, R. S., and Paulin, J.-P. 1994. Frequency and diversity of antibiotic production by putative Erwinia herbicola strains. J. Appl. Bacteriol. 76:603-607.

40. Wright, S. A., and Beer, S. V. 1996. The role of antibiotics in biological control of fire blight by Erwinia herbicola strain Eh318. Acta Hortic. 411:309-311.

41. Wright, S. A., Zumhoff, C. H., Schneider, L., and Beer, S. V. 2001. Pantoea agglomerans strain Eh318 produces two antibiotics that inhibit Erwinia amylovora in vitro. Appl. Environ. Microbiol. 67:284-292.

42. Zhang, Y., Bak, D. D., Heid, H., and Geider, K. 1999. Molecular characterization of a protease secreted by Erwinia amylovora. J. Mol. Biol. 289:1239-1251. 